\title{
Erratum to: Analysis and Optimization of Differential Systems
}

\author{
Viorel Barbu ${ }^{1}$, Irena Lasiecka ${ }^{2}$, Dan Tiba ${ }^{3}$, and Constantin Varsan ${ }^{4}$ \\ 1 University of Iasi, Romania \\ 2 University of Virginia, Charlottesville, USA \\ 3 Weierstrass Institute, Berlin, Germany \\ 4 Institute of Mathematics, Bucharest, Romania
}

\section{Erratum to:}

\section{Barbu et al. (Eds.)}

Analysis and Optimization of

Differential Systems

\section{DOI: $10.1007 / 978-0-387-35690-7$}

The book was inadvertently published with an incorrect name of the copyright holder. The name of the copyright holder for this book is: (c) IFIP International Federation for Information Processing. The book has been updated with the changes.

The updated original online version for this book can be found at DOI: 10.1007/978-0-387-35690-7 